Tetrahedron Letters

journal homepage: www.elsevier.com

\title{
Computational predictions of substituted benzyne and indolyne regioselectivities
}

\author{
Elias Picazo, K. N. Houk, * and Neil K. Garg*
}

ARTICLE INFO

Article history:

Received

Received in revised form

Accepted

Available online

Dedicated to Professor Harry H. Wasserman

Keywords:

heterocycles

arynes

computations

regioselectivities

hetarynes
ABSTRACT

A computational study using DFT methods was performed for an array of mono and disubstituted benzynes and indolynes. The inherent distortion present in the geometry-optimized structures predicts the regioselectivity of aryne trapping by nucleophiles or cycloaddition partners. These studies will serve to enable the further use of unsymmetrical arynes in organic synthesis.

2014 Elsevier Ltd. All rights reserved.

\author{
* Corresponding author. Tel.: +1-310-206-0515; fax: +1-310-206-1843; e-mail: \\ houk@chem.ucla.edu \\ * Corresponding author. Tel.: +1-310-825-1536; fax: +1-310-206-1843; e-mail: \\ neilgarg@chem.ucla.edu
}

Over the past $10-15$ years there has been resurgence in the field of aryne chemistry. ${ }^{1}$ Arynes were once avoided because of their high reactivity, but chemists have now demonstrated that arynes can be strategically employed in a host of synthetic applications. Our laboratories have been interested in harnessing substituted arynes and heterocyclic arynes to build complex scaffolds, ${ }^{2}$ especially those seen in drugs and natural products. These efforts have led to the aryne distortion/interaction model, ${ }^{2 \mathrm{c}, 2 \mathrm{~d}, 3,4}$ which explains aryne regioselectivities and can also be used to make reliable regioselectivity predictions. Following our recent regioselectivity studies of 3-substituted benzynes ${ }^{2 \mathrm{p}}$ and substituted indolynes, ${ }^{2 \mathrm{~d}, 2 \mathrm{e}, 2 \mathrm{~m}}$ we now report regioselectivity predictions for a number of disubstituted benzynes and substituted indolynes. We expect our findings will help propel the further exploitation of unsymmetrical arynes in synthesis.

A brief summary of the predictive powers of the aryne distortion model, as applied to various 3 -substituted benzynes, is provided in Table 1. First, the geometry-optimized structure of a given unsymmetrical aryne is obtained using DFT calculations. ${ }^{5,6,7}$ These calculations provide the internal angles of each alkyne terminus. The site with the larger internal angle is the preferred site of attack by nucleophiles. ${ }^{8}$ Additionally, the degree of distortion (as measured by the difference in angles) can be used to provide an estimate of regioselectivity. Even a mild degree of distortion (e.g., $4^{\circ}$ or greater), typically corresponds to synthetically useful levels of selectivity. As shown for benzynes substituted at C3 with an inductively electron-withdrawing group (entries 1-5), nucleophilic addition is predicted to occur with a preference for attack at $\mathrm{C} 1$. Generally speaking, distortion decreases in moving from the most inductively withdrawing groups (entries 1 and 2) to the least withdrawing group (entry 5), which has been validated experimentally. ${ }^{2 \mathrm{p}}$
Table 1. Distortion analysis of 3-substituted benzynes due to the presence of inductively withdrawing groups.

Entry Aryne $\begin{gathered}\begin{array}{c}\text { Geometry-optimized } \\ \text { structure" }\end{array} \\ \begin{array}{c}\text { Site of attack } \\ \text { (angle difference) }\end{array}\end{gathered} \begin{gathered}\text { Regioselectivity } \\ \text { (N-Me-aniline) }\end{gathered}$

Aryne Distortion Model - Predictive Capabilities - nucleophilic addition occurs at the aryne terminus with the larger internal angle - degree of distortion correlates with regioselectivity trends $\left(>4^{\circ}\right.$ angle difference implies synthetically useful selectivities)

${ }^{a}$ Geometry optimizations were performed using DFT methods (B3LYP/631G*; B3LYP/LACVP was used for 3-iodobenzyne (entry 5)). ${ }^{\text {b Known }}$ regioselectivities for the addition of $N$-Me-aniline to each aryne (ref $2 \mathrm{p}$ ). 
Tetrahedron

We studied benzynes bearing two substituents adjacent to the triple bond, as these have not been assessed previously using the aryne distortion model. An analysis of several 6-substituted 3fluorobenzynes is shown in Table 2. Fluoride dominates regioselectivity in every case. Nucleophilic addition is predicted to occur at $\mathrm{C} 1$ due to the distortion introduced by the electronegative fluoride substituent. Selectivity increases as the C6-substituent becomes less electron-withdrawing.

Table 2. Distortion analysis of 3-fluorobenzynes bearing a C6 inductively-withdrawing substituent.

Entry Aryne $\begin{gathered}\text { Geometry-optimized } \\ \text { structure" }\end{gathered} \quad \begin{gathered}\text { Site of attack } \\ \text { (angle difference) }\end{gathered}$

a Geometry optimizations were performed using DFT methods (B3LYP/631G*; B3LYP/LACVP was used for 3-fluoro-6-iodobenzyne (entry 4)).

We also examined the distortion present in 3-substituted 6methoxybenzynes (Table 3 ). The inductively withdrawing fluoride group governs regioselectivity in the case of entry 1 . However, for the less electronegative halides, $\mathrm{Cl}, \mathrm{Br}$, and $\mathrm{I}$, the methoxy group controls aryne distortion (entries 2-4). Accordingly, nucleophilic addition is predicted to occur at $\mathrm{C} 2$ in these three cases.

Indolynes are an important class of arynes that have gained recent attention. ${ }^{9}$ In addition to serving as building blocks for medicinally-privileged indoles, indolynes and close relatives have been used as intermediates in the total syntheses of several complex alkaloids. ${ }^{2-o}$ Although the effect of $N$-substituents on indolyne distortion has been previously examined computationally and experimentally, ${ }^{2 \mathrm{~d}}$ arene substituent effects on indolyne distortion have been largely neglected. ${ }^{10}$

Table 4 provides a distortion analysis for the 4,5-indolyne and several C6-substituted derivatives. As we have shown previously, the unsubstituted 4,5 -indolyne ${ }^{11}$ is distorted such that nucleophilic addition occurs at C5 (entry 1). Interestingly, the presence of a 6-methoxy group overturns this distortion, such that nucleophilic addition is expected to occur at $\mathrm{C} 4$ (entry 2). A similar prediction is seen for $\mathrm{F}, \mathrm{Cl}$, and $\mathrm{Br}$ substituents (entries 3-5, respectively). Finally, in the case of the 6-iodo-4,5-indolyne, the aryne distortion model predicts little unsymmetrical distortion and, consequently, low regioselectivities. ${ }^{12}$
Table 3. Distortion analysis of 6-methoxybenzynes bearing a C3 inductively withdrawing substituent.

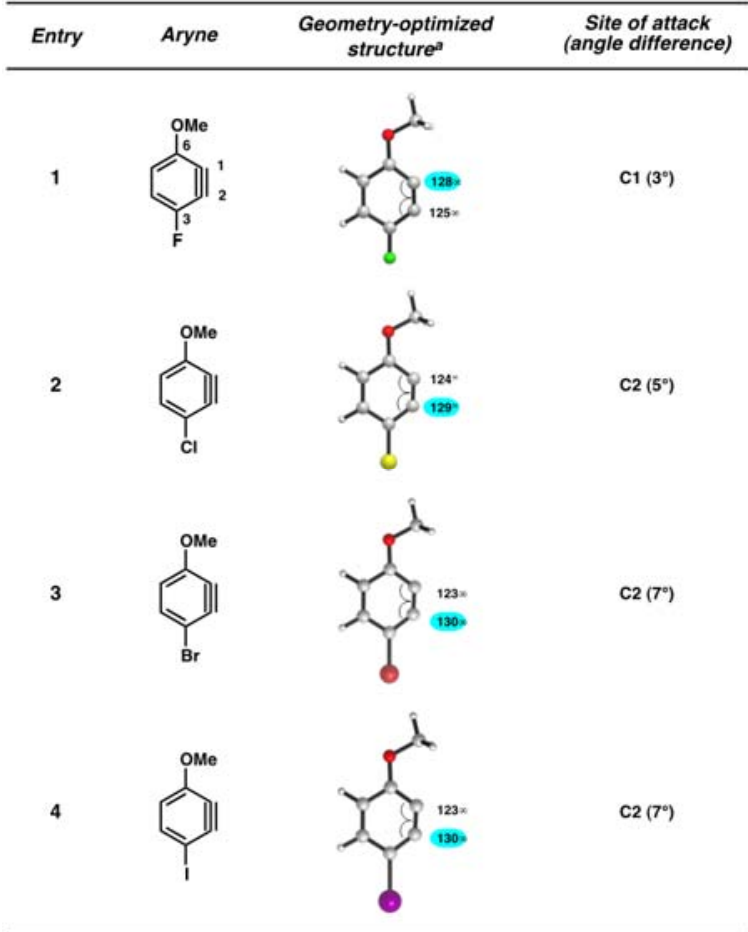

${ }^{a}$ Geometry optimizations were performed using DFT methods (B3LYP/631G*; B3LYP/LACVP was used for 6-methoxy-3-iodobenzyne (entry 4)).

Table 4. Distortion analysis of 4,5-indolynes.

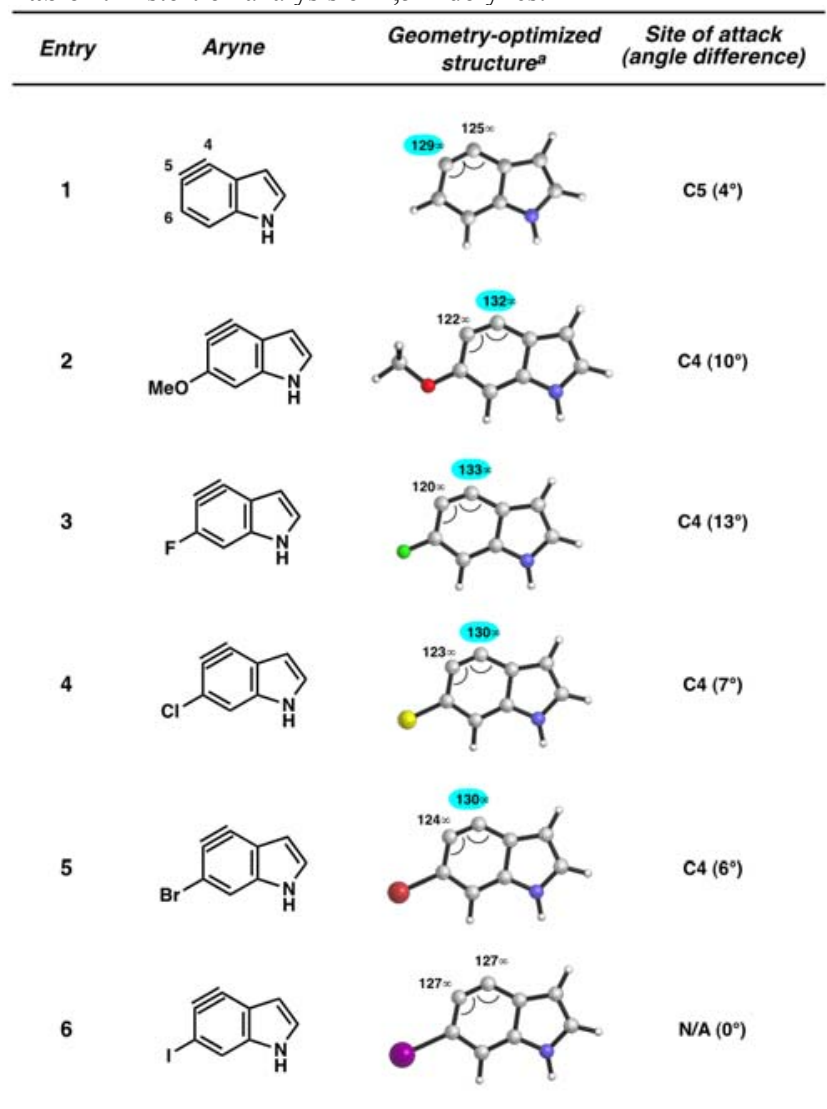

${ }^{a}$ Geometry optimizations were performed using DFT methods (B3LYP/631G*; B3LYP/LACVP was used for 6-iodo-4,5-indolyne (entry 6)). 
As shown in Table 5, we have also studied substituent effects for 5,6-indolynes. The parent 5,6-indolyne shows minor distortion and predicted regioselectivities that favor nucleophilic addition occurring at $\mathrm{C} 5$ (entry 1 ). ${ }^{2 \mathrm{~d}}$ The influence of $\mathrm{C} 4$ and $\mathrm{C} 7$ substituents were examined. C7 substituents generally lead to an increase in distortion and predicted regioselectivities; these results are given in the Supplementary Material. The presence of C4 inductively withdrawing substituents, however, leads to an overturning of the predicted regioselectivity such that C6 attack is expected to be favored (entries 2-6). Distortion is greatest in the case of the most electron-withdrawing substituents (entries 2 and 3) and becomes less significant in the cases of the $\mathrm{Cl}, \mathrm{Br}$, and I substituted analogs (entries 4-6, respectively).

Table 5. Distortion analysis of 5,6-indolynes.

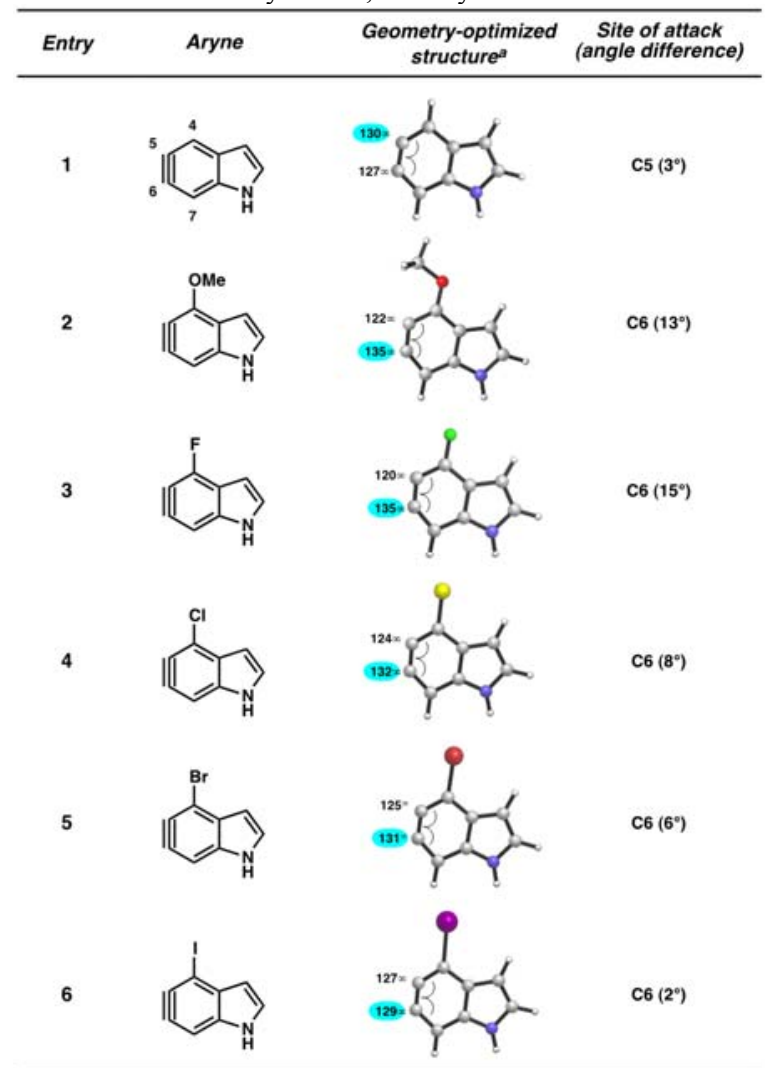

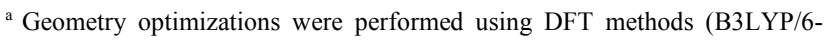
31G*; B3LYP/LACVP was used for 4-iodo-5,6-indolyne (entry 6)).

Finally, we have analyzed the distortion in several 6,7indolynes (Table 6). The 6,7-indolyne is known to react with high regioselectivity for nucleophilic addition at $\mathrm{C} 6,{ }^{2 \mathrm{~d}}$ which is consistent with the significant unsymmetrical distortion seen in the geometryoptimized structure (entry 1 ; ca. $18^{\circ}$ ). Thus, we were curious if it would be possible to overturn this inherent selectivity using substituents. Although the presence of substituents on 6,7-indolynes partially counters the inherent selectivity, we predict that attack at $\mathrm{C} 6$ is still favored in nearly all cases (entries 2-6). For 5-fluoro-6,7indolyne, selectivity is expected to be poor and may indeed favor nucleophilic attack occurring at $\mathrm{C} 7$.

In summary, we have applied the distortion/interaction model to a variety of mono and disubstituted benzynes and substituted indolynes. These studies give regioselectivity predictions using straightforward DFT calculations. We anticipate that our results will help encourage the use of unsymmetrical arynes in the synthesis of complex molecules and drug scaffolds.
Table 6. Distortion analysis of 6,7-indolynes.

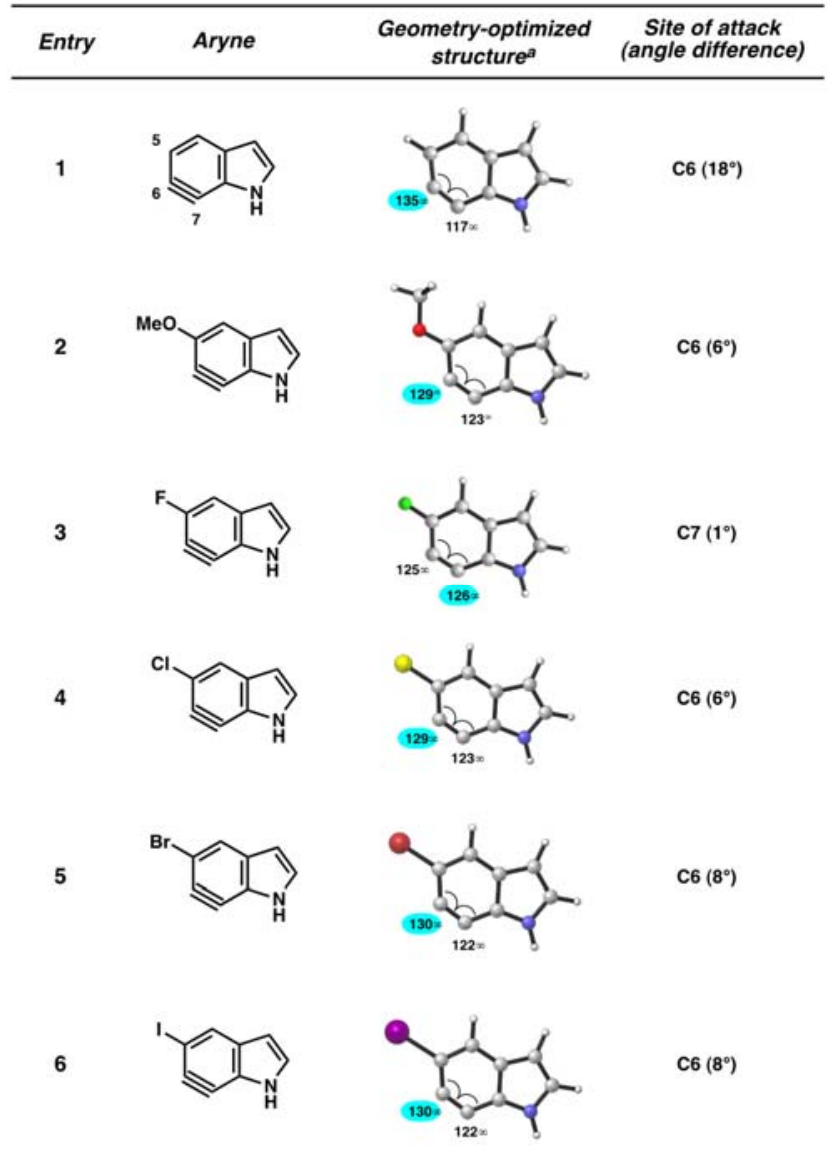

${ }^{a}$ Geometry optimizations were performed using DFT methods (B3LYP/631G*; B3LYP/LACVP was used for 5-iodo-6,7-indolyne (entry 6)).

\section{Acknowledgments}

The authors are grateful to the NIH-NIGMS (R01 GM090007 to N. K. G.), the National Science Foundation (CHE-0548209 to K. N. H.), Bristol-Myers Squibb, DuPont, the S. T. Li Foundation, the Dreyfus Foundation, the University of California, Los Angeles, and the UCLA Cota Robles Fellowship Program (E. P.) for financial support.

\section{Supplementary Material}

Supplementary material with this article can be found in the online version, at http:

\section{References and notes}

1. For reviews, see: (a) Pellissier, H.; Santelli, M. Tetrahedron 2003, 59, 701730; (b) Wenk, H. H.; Winkler, M.; Sander, W. Angew. Chem. Int. Ed. 2003 , 42, 502-528; (c) Sanz, R. Org. Prep. Proced. Int. 2008, 40, 215-291; (d) Bronner, S. M.; Goetz, A. E.; Garg, N. K. Synlett 2011, 18, 2599-2604; (e) Tadross, P. M.; Stoltz, B. M. Chem. Rev. 2012, 112, 3550-3577; (f) Gampe, C. M.; Carreira, E. M. Angew. Chem. Int. Ed. 2012, 51, 3766-3778; (g) Yoshida, H.; Takaki, K. Synlett 2012, 23, 1725-1732; (h) Dubrovskiy, A. V.; Markina, N. A.; Larock, R. C. Org. Biomol. Chem. 2013, 11, 191-218; (i) Wu, C.; Shi, F. Asian J. Org. Chem. 2013, 2, 116-125; (j) Hoffmann, R. W.; Suzuki, K. Angew. Chem. Int. Ed. 2013, 52, 2655-2656; (k) Bhunia, A.; Biji, A. T. Synlett 2014, 25, 608-614; (1) Goetz, A. E.; Garg, N. K. J. Org. Chem. 2014, 79, 846-851; (m) Goetz, A. E.; Shah, T. K.; Garg, N. K. Chem. Commun. 2015, 15, 34-45. 
2. (a) Bronner, S. M.; Bahnck, K. B.; Garg, N. K. Org. Lett. 2009, 11, 10071010; (b) Tian, X.; Huters, A. D.; Douglas, C. J.; Garg, N. K. Org. Lett. 2009, 11, 2349-2351; (c) Cheong, P. H.-Y.; Paton, R. S.; Bronner, S. M.; Im, G.-Y. J.; Garg, N. K.; Houk, K. N. J. Am. Chem. Soc. 2010, 132, 1267-1269; (d) Im, G.-Y. J.; Bronner, S. M.; Goetz, A. E.; Paton, R. S.; Cheong, P. H.-Y.; Houk, K. N.; Garg, N. K. J. Am. Chem. Soc. 2010, 132, 17933-17944; (e) Bronner, S. M.; Goetz, A. E.; Garg, N. K. J. Am. Chem. Soc. 2011, 133, 3832-3835; (f) Bronner, S. M.; Mackey, J. L.; Houk, K. N.; Garg, N. K. J. Am. Chem. Soc. 2012, 134, 13966-13969; (g) Goetz, A. E.; Bronner, S. M.; Cisneros, J. D.; Melamed, J. M.; Paton, R. S.; Houk, K. N.; Garg, N. K. Angew. Chem. Int. Ed. 2012, 51, 2758-2762; (h) Goetz, A. E.; Garg, N. K. Nat. Chem. 2013, 5, 54-60; (i) Huters, A. D.; Quasdorf, K. W.; Styduhar, E. D.; Garg, N. K. J. Am. Chem. Soc. 2011, 133, 15797-15799; (j) Quasdorf, K. W.; Huters, A. D.; Lodewyk, M. W.; Tantillo, D. J.; Garg, N. K. J. Am. Chem. Soc. 2012, 134, 1396-1399; (k) Styduhar, E. D.; Huters, A. D.; Weires, N. A.; Garg, N. K. Angew. Chem. Int. Ed. 2013, 52, 12422-12425; (1) Goetz, A. E.; Silberstein, A. L.; Corsello, M. A.; Garg, N. K. J. Am. Chem. Soc. 2014, 136, 3036-3039; (m) Fine Nathel, N. F.; Shah, T. K.; Bronner, S. M.; Garg, N. K. Chem. Sci. 2014, 5, 2184-2190; (n) Medina, J. M.; McMahon, T. C.; Jiménez-Osés, G.; Houk, K. N.; Garg, N. K. J. Am. Chem. Soc. 2014, 136, 14706-14709; (o) Weires, N. A.; Styduhar, E. D.; Baker, E. L.; Garg, N. K. J. Am. Chem. Soc. 2014, 136, 14710-14713; (p) Medina, J. M.; Mackey, J. L.; Garg, N. K; Houk, K. N. J. Am. Chem. Soc. 2014, 136, 15798-15805.

3. The distortion / interaction model is also referred to as the activation-strain model according to Bickelhaupt; for references, see: (a) van Zeist, W.-J.; Bickelhaupt, F. M. Org. Biomol. Chem. 2010, 8, 3118-3127; (b) Fernández, I.; Cossío, F. P.; Bickelhaupt, F. M. J. Org. Chem. 2011, 76, 2310-2314; (c) Fernández, I.; Bickelhaupt, F. M. J. Comput. Chem. 2012, 33, 509-516; (d) Fernández, I.; Sola, M.; Bickelhaupt, F. M. Chem. Eur. J. 2013, 19, 74167422 .

4. For non-aryne applications of the distortion / interaction model, see: (a) Ess, D. H.; Houk, K. N. J. Am. Chem. Soc. 2007, 129, 10646-10647; (b) Legault, C. Y.; Garcia, Y.; Merlic, C. A.; Houk, K. N. J. Am. Chem. Soc. 2007, 129, 12664-12665; (c) Ess, D. H.; Houk, K. N. J. Am. Chem. Soc. 2008, 130, 10187-10198; (d) Lam, Y.-h.; Cheong, P. H.-Y.; Blasco Mata, J. M.; Stanway, S. J.; Gouverneur, V.; Houk, K. N. J. Am. Chem. Soc. 2009, 131, 1947-1957; (e) Hayden, A. E.; Houk, K. N. J. Am. Chem. Soc. 2009, 131, 4084-4089; (f) Garcia, Y.; Schoenebeck, F.; Legault, C. Y.; Merlic, C. A.; Houk, K. N. J. Am. Chem. Soc. 2009, 131, 6632-6639. (g) Schoenebeck, F.; Ess, D. H.; Jones, G. O.; Houk, K. N. J. Am. Chem. Soc. 2009, 131, 81218133; (h) Osuna, F.; Houk, K. N. Chem. Eur. J. 2009, 15, 13219-13231; Kolakowski, R. V.; Williams, L. J. Nat. Chem. 2010, 2, 303-307. (i) Paton, R. S.; Kim, S.; Ross, A. G.; Danishefsky, S. J.; Houk, K. N. Angew. Chem. Int. Ed. 2011, 50, 10366-10368; (j) Lan, Y.; Wheeler, S. E.; Houk, K. N. J. Chem. Theory Comput. 2011, 7, 2104-2111; (k) Liang, Y.; Mackey, J. L.; Lopez, S. A.; Liu, F.; Houk, K. N. J. Am. Chem. Soc. 2012, 134, 17904 17907; (1) Gordon, C. G.; Mackey, J. L.; Jewett, J. C.; Sletten, E. M.; Houk, K. N.; Bertozzi, C. R. J. Am. Chem. Soc. 2012, 134, 9199-9208; (m) Lopez, S. A.; Munk, M. E.; Houk, K. N. J. Org. Chem. 2013, 78, 1576-1582; (n) Lopez, S. A.; Houk, K. N. J. Org. Chem. 2013, 78, 1778-1783; (o) Zou, L.; Paton, R. S.; Eschenmoser, A.; Newhouse, T. R.; Baran, P. S.; Houk, K. N. J. Org. Chem. 2013, 78, 4037-4048; (p) Kamber, D. N.; Nazarova, L. A.; Liang, Y.; Lopez, S. A.; Patterson, D. M.; Shih, H.-W.; Houk, K. N.; Prescher, J. A. J. Am. Chem. Soc. 2013, 135, 13680-13683; (q) Liu, F.; Paton, R. S.; Kim, S.; Liang, Y.; Houk, K. N. J. Am. Chem. Soc. 2013, 135, 15642-15649; (r) Yang, J.; Liang, Y.; Šečkutè, J.; Houk, K. N.; Devaraj, N. K. Chem. Eur. J. 2014, 20, 3365-3375; (s) Hong, X.; Liang, Y.; Griffith, A. K.; Lambert, T. H.; Houk, K. N. Chem. Sci. 2014, 5, 471-475; (t) Green, A. G.; Liu, P.; Merlic, C. A.; Houk, K. N. J. Am. Chem. Soc. 2014, 136, 45754583; (u) Liu, F.; Liang, Y.; Houk, K. N. J. Am. Chem. Soc. 2014, 136, 11483-11493.

5. Geometry-optimizations were carried out using B3LYP/6-31G* (or B3LYP/LACVP in the case of iodide-containing arynes) with MacSpartan software. Spartan '10; Wavefunction, Inc: Irvine, CA, 2010.

6. Images of geometry-optimized structures were prepared using CYLview: Legault, C. Y. CYLview, 1.0b; Université de Sherbrooke: Québec, Montreal, Canada, 2009; http://www.cylview.org.

7. The distortion present in each unsymmetrical aryne is caused by the proximal inductively withdrawing groups, which deform the triple bond as a result of Bent's rule; Bent, H. Chem. Rev. 1961, 61, 275-311.

8. This pathway is favored because it requires minimal distortion to reach the transition state. For more information regarding the aryne distortion model, see references $2 \mathrm{c}, \mathrm{d}$.
9. For a recent review, see reference $1 \mathrm{~m}$.

10. We have previously studied the 6-bromo-4,5-indolyne and employed this species in the total synthesis of several indolactam alkaloids; see references $2 \mathrm{e}$ and $2 \mathrm{~m}$.

11. A stable silyltriflate precursor to the parent 4,5-indolyne is commercially available from Aldrich Chemical Co., Inc. (product \#L511625).

12. The predictive capabilities of the aryne distortion model strictly using geometry-optimization does not take into account steric factors. As such, one might expect nucleophilic addition in the case of 6-iodo-4,5-indolyne (Table 4 , entry 6) to occur with some selectivity for nucleophilic addition at $\mathrm{C} 4$. 


\section{Graphical Abstract}

Computational predictions of substituted benzyne and indolyne regioselectivities

Elias Picazo, K. N. Houk, Neil K. Garg
Leave this area blank for abstract info.

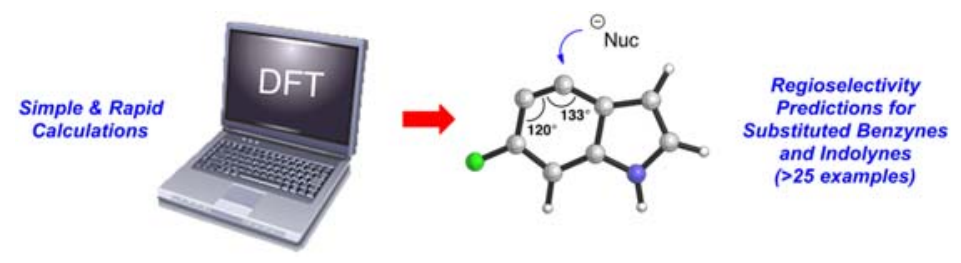

